\title{
FY-12 INL Krypton Capture Activities Supporting the Off-Gas Sigma Team
}

\author{
Troy G. Garn
}

Mitchell R. Greenhalgh

Jack D. Law

August 2012

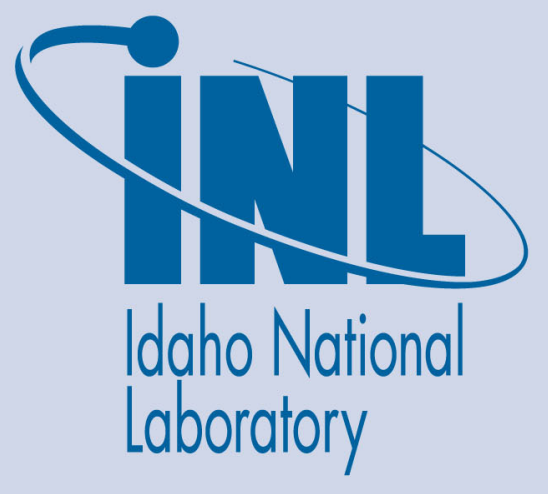

The INL is a U.S. Department of Energy National Laboratory operated by Battelle Energy Alliance 
INL/EXT-12-26994

\title{
FY-12 INL Krypton Capture Activities Supporting the Off-Gas Sigma Team
}

\author{
Troy G. Garn \\ Mitchell R. Greenhalgh \\ Jack D. Law
}

August 2012

\section{Idaho National Laboratory \\ Fuel Cycle Research \& Development Idaho Falls, Idaho 83415}

http://www.inl.gov

Prepared for the

U.S. Department of Energy

Office of Nuclear Energy

Under DOE Idaho Operations Office

Contract DE-AC07-05ID14517 


\section{DISCLAIMER}

This information was prepared as an account of work sponsored by an agency of the U.S. Government. Neither the U.S. Government nor any agency thereof, nor any of their employees, makes any warranty, expressed or implied, or assumes any legal liability or responsibility for the accuracy, completeness, or usefulness, of any information, apparatus, product, or process disclosed, or represents that its use would not infringe privately owned rights. References herein to any specific commercial product, process, or service by trade name, trade mark, manufacturer, or otherwise, does not necessarily constitute or imply its endorsement, recommendation, or favoring by the U.S. Government or any agency thereof. The views and opinions of authors expressed herein do not necessarily state or reflect those of the U.S. Government or any agency thereof. 


\section{SUMMARY}

Tasks performed this year by INL Kr capture off-gas team members can be segregated into three separate sub-sections which include: 1) The development and testing of a new engineered form sorbent, 2) An initial NDA gamma scan effort performed on the drum containing the Legacy $\mathrm{Kr}-85$ sample materials, and 3) Collaborative research efforts with PNNL involving the testing of the NiDOBDC MOF and an initial attempt to make powdered chalcogel material into an engineered form using our binding process. This document describes the routes to success for the three task sub-sections.

Tests using the newly engineered sorbent (AgZ-PAN) were completed with numerous test gases composed of varying mixtures of $\mathrm{N}_{2}, \mathrm{O}_{2}, 150 \mathrm{ppm} \mathrm{Kr}$ and $100 \mathrm{ppm}$ Xe. Tests were performed at ambient and $191 \mathrm{~K}$ temperatures. Test results were compared to test results using the HZ-PAN sorbent indicating that the AgZ-PAN exhibited higher Xe capacity at ambient temperature than the HZPAN sorbent tested previously. However the comparison results for Xe capacities at $191 \mathrm{~K}$ indicate the HZ-PAN has higher capacity for Xe and slightly lower $\mathrm{Kr}$ capacity than AgZ-PAN for the two gases having $\mathrm{Kr}$ and Xe with or without $\mathrm{N}_{2}$. The results of this testing indicate the presence of silver appears to increase capacities at ambient temperature; however surface area appears to influence capacities at $191 \mathrm{~K}$.

A preliminary non-destructive analysis using a gamma scan detection system was performed on the outer container housing the legacy sample materials. Gamma scan results indicate the prominent gamma emitting isotope present in the drum is $\mathrm{Kr}-85$. At the time of this writing, it is uncertain if the tasks documented in the strategy plan developed in FY-11 will be completed. The accomplishment of tasks at MFC relating to research involving radiation and contamination has become more difficult due to the backlog of work related to safety stand downs. As such, FY-13 work should include discussion into alternative or reduced work scope aside from that documented in the strategy plan.

A preliminary sequence of capacity tests were performed on a Ni-DOBDC MOF material supplied by PNNL. The test gas was $150 \mathrm{ppm} \mathrm{Kr}$ and $1000 \mathrm{ppm}$ $\mathrm{Xe}$ in air at flow rates of 10,20 and $50 \mathrm{sccm}$ (superficial velocity range 0.2 to 1.2 $\mathrm{cm} / \mathrm{s}$ ). Capacity measurements could not be made for either $\mathrm{Kr}$ or Xe using the cryostat at ambient temperature. The material was retested in a smaller column outside of the cryostat with the Xe capacity averaging $8.25 \mathrm{mmol} / \mathrm{kg}$ which agreed very favorably with PNNL reported results of $9.31 \mathrm{mmol} / \mathrm{kg}$.

A scoping effort to prepare an engineered form material using PNNL-3 chalcogel powder was completed. A final engineered form was achieved with a composition estimated at $55 \mathrm{wt} \%$ chalcogel and $45 \mathrm{wt} \%$ binder. A BET measurement of the engineered form beads resulted in a surface area of only 50 $\mathrm{m}^{2} / \mathrm{g}$, which may hinder the performance of the chalcogels. 


\section{CONTENTS}

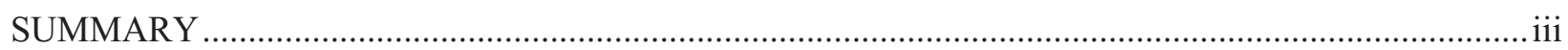

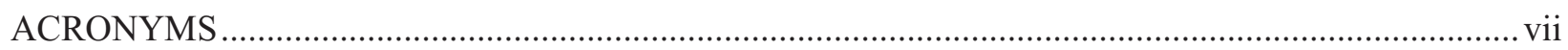

1. DEVELOPMENT AND TESTING OF A NEW NOVEL SORBENT ........................................... 1

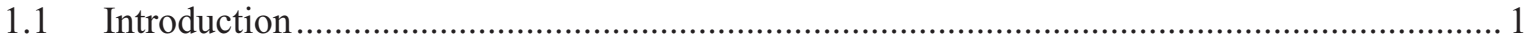

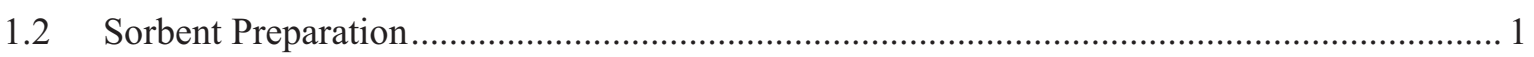

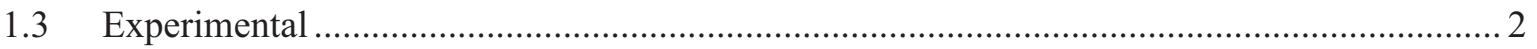

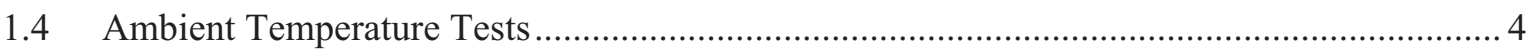

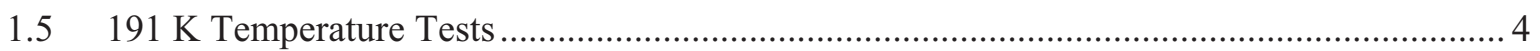

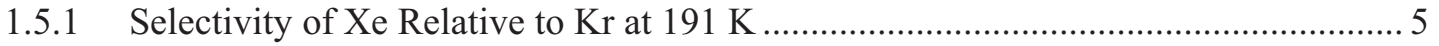

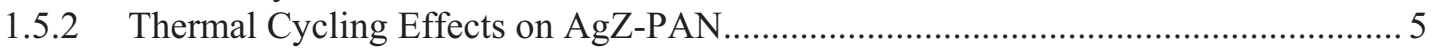

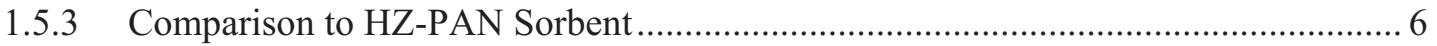

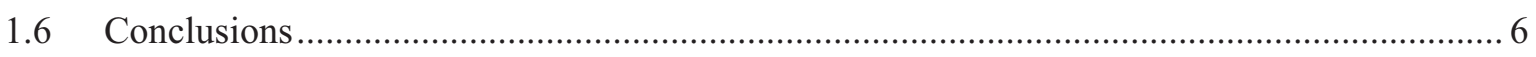

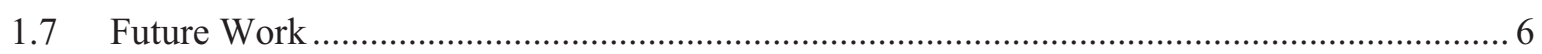

2. NON-DESTRUCTIVE GAMMA SCAN ANALYSIS OF KR-85 LEGACY SAMPLES............... 8

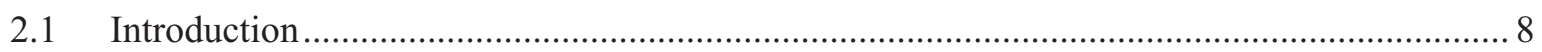

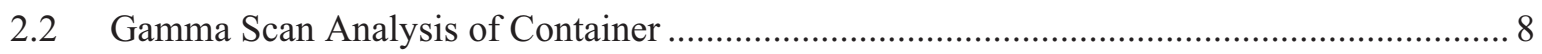

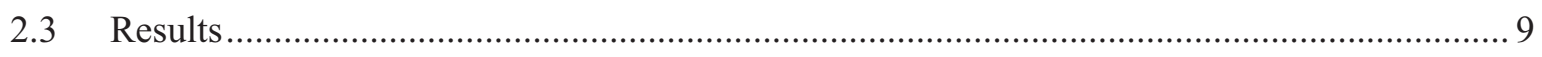

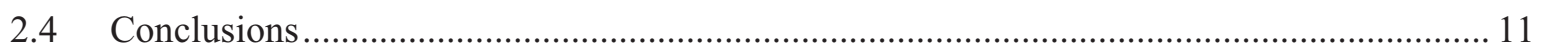

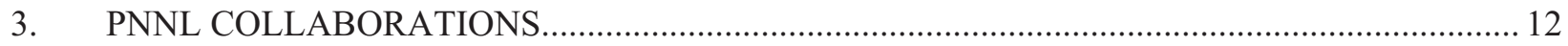

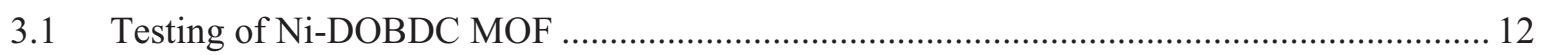

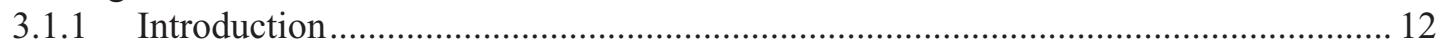

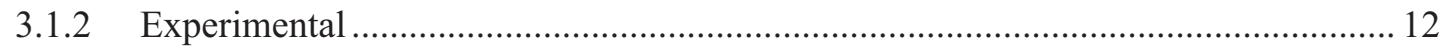

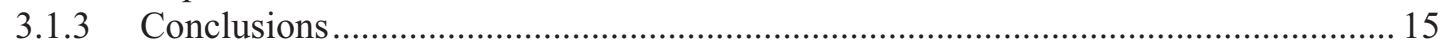

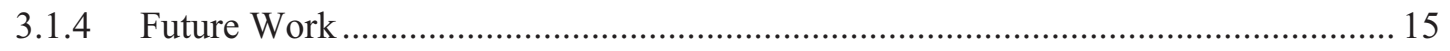

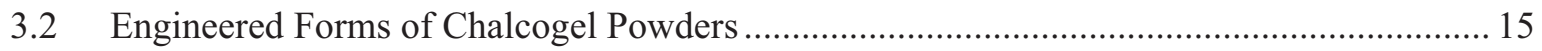

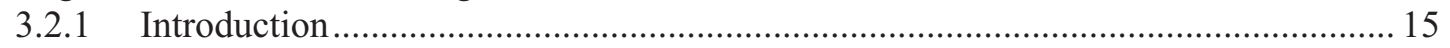

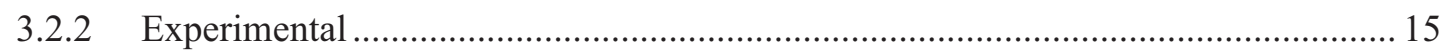

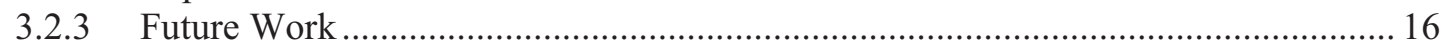

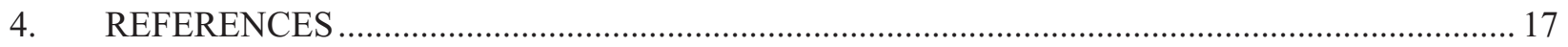

\section{FIGURES}

Figure 1. SEM photos showing a sorbent bead, a bead cut in half, and a close up of the interior of the

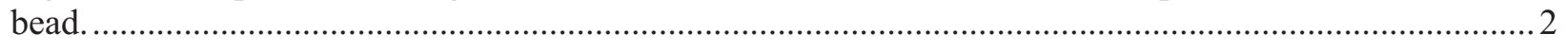

Figure 2. Photo of the cryostat setup used for testing (GC not shown) ................................................ 3

Figure 3. Drum containing Kr-85 samples with gamma scan equipment in HFEF at MFC...................... 8

Figure 4. Drum side 1: Identified peaks include Kr-85, Cs-137, Co-60, Sum peaks, Tl-208.................... 9

Figure 5. Drum side 2: Identified peaks include Kr-85, Cs-137, Co-60, Sum peaks, Tl-208................... 10 
Figure 6. Drum side 3: Identified peaks include Kr-85, Cs-137, Co-60, Sum peaks, Tl-208................... 10

Figure 7. Drum side 4: Identified peaks include Kr-85, Cs-137, Co-60, Sum peaks, Tl-208 ................... 11

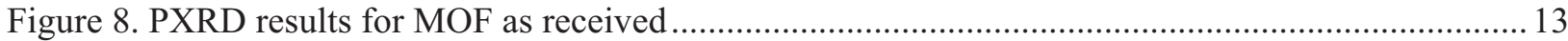

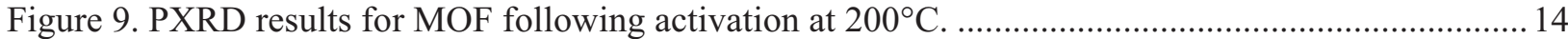

Figure 10. Photo of engineered form PNNL-3 chalcogel. ................................................................. 16

TABLES

Table 1. Xe capacities for AgZ-PAN at ambient temperature ................................................................. 4

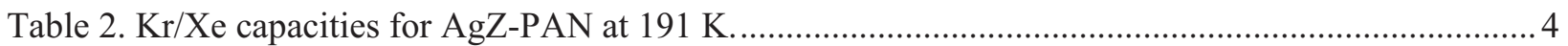

Table 3. Xe selectivity relative to $\mathrm{Kr}$ for AgZ-PAN at $191 \mathrm{~K}$............................................................

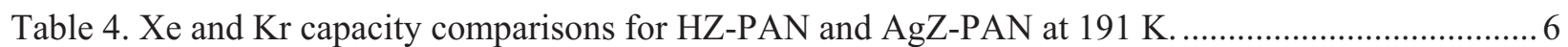

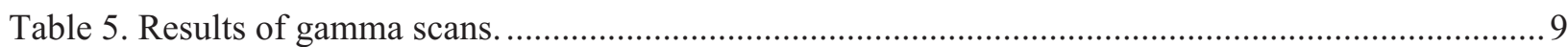

Table 6. Cs-137 and Co-60 count rate values for four drum sides. ........................................................ 11 


\section{ACRONYMS}

$\begin{array}{ll}\text { 1M2P } & \text { 1-methyl-2-pyrillidinone } \\ \text { AgZ-PAN } & \text { silver exchanged mordenite-polyacrylonitrile sorbent } \\ \text { BET } & \text { Brunauer, Emmett, and Teller theory } \\ \text { CPS } & \text { counts per second } \\ \text { DMAC } & \text { dimethylacetamide } \\ \text { EDS } & \text { energy dispersive spectroscopy } \\ \text { GC-TCD } & \text { gas chromatograph with thermal conductivity detector } \\ \text { HFEF } & \text { Hot Fuels Examination Facility } \\ \text { HiPed } & \text { hot isostatically pressed } \\ \text { HZ-PAN } & \text { hydrogen mordenite-polyacrylonitrile sorbent } \\ \text { ICP-MS } & \text { inductively coupled plasma - mass spectroscopy } \\ \text { INL } & \text { Idaho National Laboratory } \\ \text { IRC } & \text { Idaho Research Center } \\ \text { K } & \text { Kelvin }\left({ }^{\circ} \text { C }+273.15\right) \\ \text { Kr } & \text { krypton } \\ \text { MFC } & \text { Materials and Fuels Complex } \\ \text { MOF } & \text { metal organic framework } \\ \text { NDA } & \text { non-destructive analysis } \\ \text { ORNL } & \text { Oak Ridge National Laboratory } \\ \text { P/P } & \text { relative pressure range } \\ \text { PNNL } & \text { Pacific Northwest National Laboratory } \\ \text { PXRD } & \text { powder x-ray diffraction } \\ \text { SEM } & \text { scanning electron microscope } \\ \text { Xe } & \text { xenon } \\ & \end{array}$




\title{
FY-12 INL Krypton Capture Activities Supporting the Off-Gas Sigma Team
}

\section{DEVELOPMENT AND TESTING OF A NEW NOVEL SORBENT}

\author{
INL Contributors: Troy Garn, Mitchell Greenhalgh, Cathy Rae and Tammy Trowbridge
}

\subsection{Introduction}

This task investigated the potential for making a new silver exchanged mordenite-polyacrylonitrile sorbent material (AgZ-PAN) capable of capturing xenon (Xe) and krypton (Kr) at temperatures ranging from ambient temperature $(294 \mathrm{~K})$ down to $190 \mathrm{~K}$. The investigation determined if the AgZ-PAN has a higher $\mathrm{Kr}$ and/or Xe capacity over the hydrogen mordenite-polyacrylonitrile (HZ-PAN) sorbent tested in FY- $11^{1}$ and looked at the possibility of using the AgZ-PAN as a Xe polishing column that could be installed upstream of a $\mathrm{Kr}$ specific column to investigate the potential increase of $\mathrm{Kr}$ capacity in a downstream Kr column. FY-11 work demonstrated that an engineered form sorbent could be prepared from a hydrogen mordenite powder with test results indicating good capacities for both $\mathrm{Xe}$ and $\mathrm{Kr}$ at $190 \mathrm{~K}$. A patent application was filed describing the preparation procedure for these engineered form novel sorbents. ${ }^{2}$

The capacity results of the AgZ-PAN were compared to the HZ-PAN results to evaluate the capacity and selectivity for both $\mathrm{Xe}$ and $\mathrm{Kr}$ in the presence of numerous test gas compositions. All FY-12 testing performed on the AgZ-PAN sorbent utilized the cryostat experimental setup located in the INL Research Center (IRC).

\subsection{Sorbent Preparation}

The sorbent was prepared by first converting a sodium form mordenite powder into a silver exchanged mordenite powder. The conversion process is accomplished by simply contacting the sodium form powder twice with a $0.1 \underline{\mathrm{M}} \mathrm{AgNO}_{3}$ solution at $\sim 80^{\circ} \mathrm{C}$ with gentle stirring. Following the second contact, the solids were filtered, rinsed thoroughly with nanopure water, and dried at $60^{\circ} \mathrm{C}$ for 12 hours. Stoichiometrically, if all of the sodium is converted, the silver composition of the converted powder would be about $10 \mathrm{wt} \%$. To ensure the conversion procedure was successful, a small mass of the converted powder was dissolved in a hydrofluoric/nitric acid mixture and submitted for inductivelycoupled plasma mass spectroscopy (ICP-MS) analysis. The results of this analysis indicated the silver content to be $10.2 \mathrm{wt} \%$. A nitrogen BET surface area measurement using a Micromeritics Surface Area Analyzer Model ASAP 2020 on the converted powder revealed a surface area of $347.2 \mathrm{~m}^{2} / \mathrm{g}$. The powder was then bound using a PAN (polyacrylonitrile) macroporous polymer at an $80 \mathrm{wt} \%$ loading. The resultant surface area of the engineered form sorbent was only $81.9 \mathrm{~m}^{2} / \mathrm{g}$. This lower than expected surface area indicated the AgZ-PAN final product was not useful for physisorption testing. A literature search revealed that there is a strong interaction of silver with sulfur which is contained in the solvent used in the binding process. ${ }^{3,4}$ Two aprotic polar solvents dimethylacetamide (DMAC) and 1-methyl-2pyrillidinone (1M2P) were selected as candidate alternatives based on low toxicity and lack of sulfur in their composition. Two sorbents were prepared with the converted powder using each candidate solvent. The beads resulting from the prepared sorbents were characteristically more brittle than those made with the original solvent and would easily collapse into a powder by applying finger pressure. BET measurements revealed very low surface area for these sorbents signifying that the use of the alternative solvents would not achieve desired results, thus they were abandoned. 
Following a thorough process of elimination involving investigating characteristics of the PAN binder, silver converted powder, alternative solvents, and the overall preparatory process, the option to simply rearrange the sorbent preparation procedure was investigated. The rearranged procedure calls to first bind the sodium mordenite powder in PAN followed by contacting the resultant Na-PAN sorbent with silver nitrate solution with very mild mixing by argon sparge at $95^{\circ} \mathrm{C}$ for 2 days. A sample of the AgZ-PAN prepared in this manner was dissolved in a hydrofluoric/nitric acid solution and submitted for ICP-MS analysis. The analysis results indicated that this procedure resulted in a final silver concentration in the final material of $8.1 \mathrm{wt} \%$, which supports a nearly complete conversion of all sodium to silver. The final surface area was measured to be $250 \mathrm{~m}^{2} / \mathrm{g}$, which is acceptable for use in the planned experiments. This AgZ-PAN material was sieved to a particle diameter range between 0.425 and $1.4 \mathrm{~mm}$ and used for all testing at ambient and $191 \mathrm{~K}$ temperatures.

Scanning electron microscope photos taken of the AgZ-PAN material included in Figure 1 show the uniformity of sorbent beads, the porosity of the interior of the beads, and the composition of the interior. Energy dispersive spectroscopy (EDS) analysis qualitatively indicated silver composition to be about $17 \%$ by weight for this particular section of the bead interior.
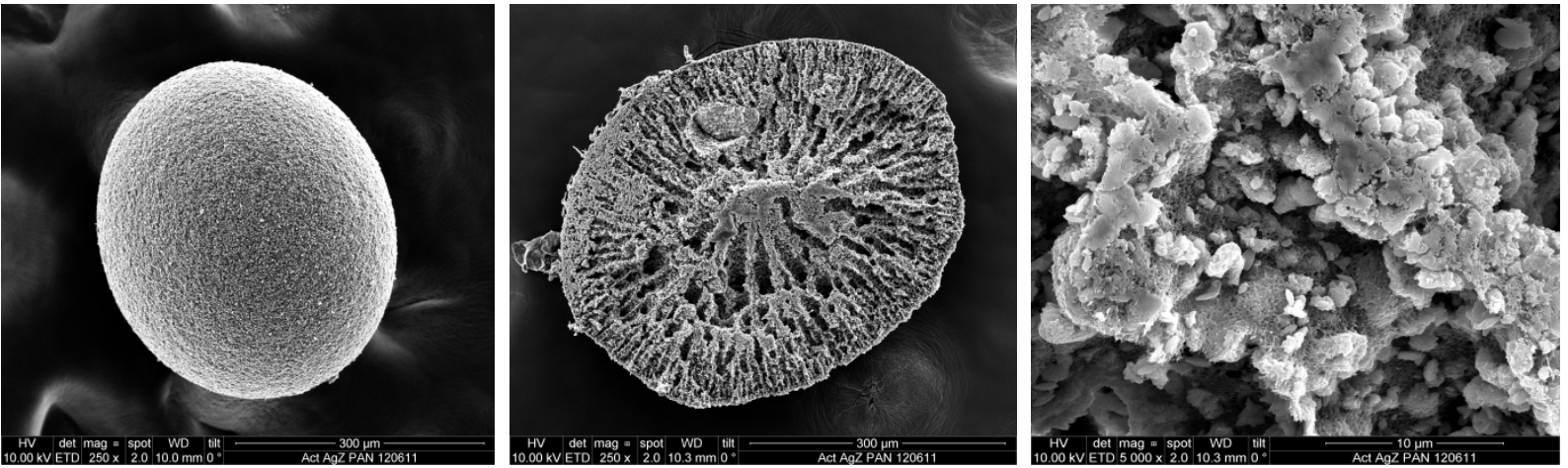

Figure 1. SEM photos showing a sorbent bead, a bead cut in half, and a close up of the interior of the bead.

\subsection{Experimental}

All testing performed using the AgZ-PAN material utilized the cryostat experimental setup as shown in Figure 2. The effluent streams were fed directly to a gas chromatograph with thermal conductivity detector (GC-TCD) for real time analyses. 


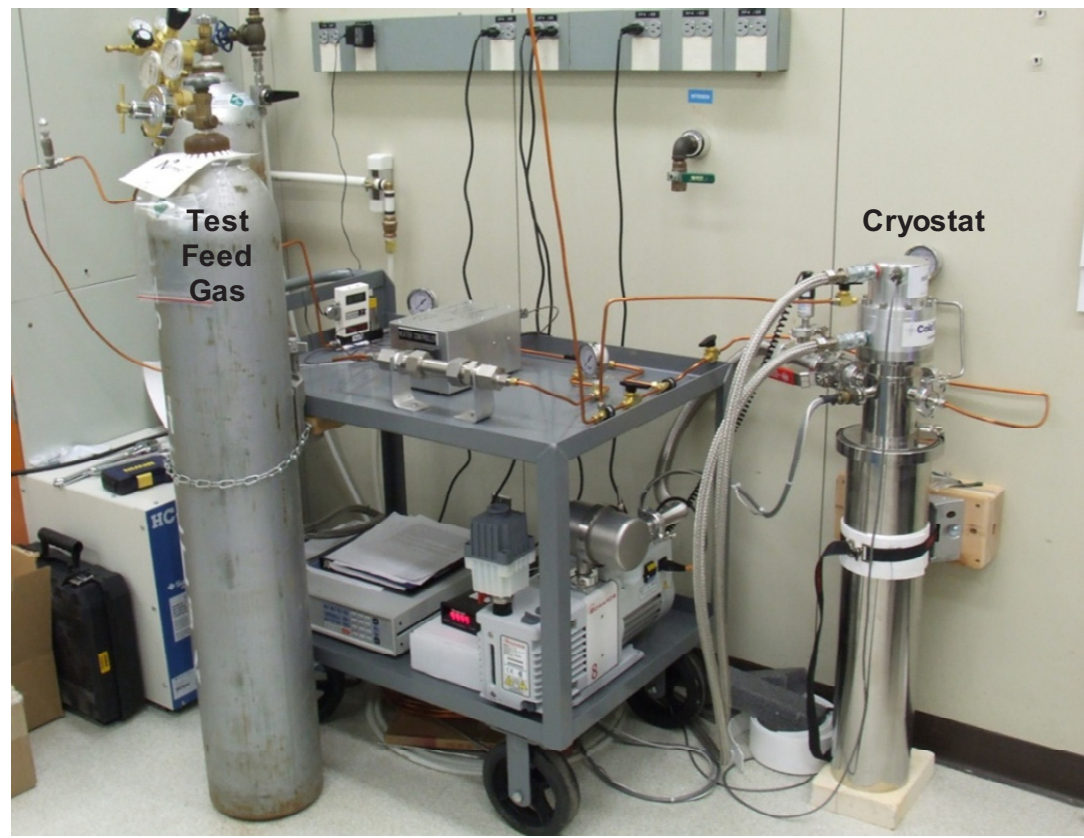

Figure 2. Photo of the cryostat setup used for testing (GC not shown).

Breakthrough curves are generated by plotting the concentration of the constituent of interest (C) in the column effluent as supplied by GC data as a function of the volume (v) of gas processed. The collected breakthrough curves are used to calculate the sorbent capacity (SC) for each constituent in the feed gas. The sorbent capacities are calculated from the following equation:

$S C=\int_{0}^{V} \frac{\left(C_{0}-C\right)}{M} d v$

where

$\mathrm{V}=$ total volume processed at breakthrough, liters

$\mathrm{C}_{0}=$ concentration in feed, $\mathrm{mol} / \mathrm{L}$

$\mathrm{C}=$ concentration in effluent at $v, \mathrm{~mol} / \mathrm{L}$

$\mathrm{M}=$ sorbent mass, grams.

Because $\mathrm{C}_{\mathrm{o}}$ and $\mathrm{M}$ are constant, Equation 1 can be rewritten as:

$S C=\frac{1}{M}\left(\mathrm{CoV}-\int_{0}^{V} C d v\right)$.

The statistical software TableCurve ${ }^{\circledR}$ from Jandel Scientific was used to find the best-fit for equations representing the breakthrough curves. The software was used to define the area below the breakthrough curve to obtain the value for the last term in Equation 2. This result was then subtracted from the total area $\mathrm{C}_{\mathrm{o}} \mathrm{V}$ to give the amount of $\mathrm{Kr}$ and $\mathrm{Xe}$ adsorbed on the material. The adsorbed amount was then divided by the sorbent bed mass to give a final sorbent capacity in $\mathrm{mmol} \mathrm{Kr}$ or Xe/kg sorbent.

A sorbent mass of 5.68 grams was placed into the cold column and inserted into the cryostat. Prior to testing, the sorbent was activated at $125^{\circ} \mathrm{C}$ for 16 hours with helium flow. The activation was performed to ensure the residual water vapor was removed from the pores, increasing availability of capture sites. 


\subsection{Ambient Temperature Tests}

Following the initial activation, AgZ-PAN evaluations at ambient temperatures were performed. Various feed gas compositions were tested to measure capacity for Xe and $\mathrm{Kr}$. Results from the testing indicated no measurable $\mathrm{Kr}$ capacity thus $\mathrm{Kr}$ results are not reported. Table 1 incorporates the gases tested with respective $\mathrm{Xe}$ measured capacities. $\mathrm{Kr}$ and $\mathrm{Xe}$ concentrations in all test gases were $150 \mathrm{ppm}$ and $1000 \mathrm{ppm}$, respectively. A gas flow of $50 \mathrm{sccm}$ equating to a superficial velocity of $1.2 \mathrm{~cm} / \mathrm{s}$ was used.

Table 1. Xe capacities for AgZ-PAN at ambient temperature

\begin{tabular}{lccc}
\hline \hline Feed Gas composition & Temp. $( \pm 1 \mathrm{~K})$ & $\begin{array}{c}\text { Flow Rate } \\
(\mathrm{sccm})\end{array}$ & Xe capacity $(\mathrm{mmol} / \mathrm{kg})$ \\
\hline \hline $\mathrm{Kr} / \mathrm{Xe} / \mathrm{Air}$ & 296 & 50 & 27.8 \\
$\mathrm{Kr} / \mathrm{Xe} / \mathrm{N}_{2} / \mathrm{He}$ & 297 & 50 & 8.5 \\
$\mathrm{Kr} / \mathrm{Xe} / \mathrm{He}$ & 295 & 50 & 31.6 \\
$\mathrm{Xe} / \mathrm{He}$ & 296 & 50 & 31.5 \\
\hline \hline
\end{tabular}

In general, the Xe capacity results at ambient temperature were very similar for all test gases tested, except the $\mathrm{Kr} / \mathrm{Xe} / \mathrm{N}_{2} / \mathrm{He}$. It is presently unclear why the Xe capacity is so much lower with this gas than the other three gases tested. One plausible explanation is that the presence of oxygen with $79 \%$ nitrogen may influence the silver crystalline structure impacting i.e. increase, capacity when compared to gas compositions with nitrogen only. It is important to note that the addition of both nitrogen and oxygen did not significantly impact the Xe capacity of the AgZ-PAN at ambient temperature.

\section{$1.5191 \mathrm{~K}$ Temperature Tests}

The lower temperature tests were performed in the same manner and followed the ambient temperature tests. Table 2 lists the $\mathrm{Kr}$ and Xe capacity results for the test gases used.

Table 2. $\mathrm{Kr} / \mathrm{Xe}$ capacities for AgZ-PAN at $191 \mathrm{~K}$.

\begin{tabular}{lcccc}
\hline \hline $\begin{array}{c}\text { Feed Gas } \\
\text { composition }\end{array}$ & Temp. (K) & $\begin{array}{c}\text { Flow Rate } \\
\text { (sccm) }\end{array}$ & $\begin{array}{c}\text { Xe capacity } \\
(\mathrm{mmol} / \mathrm{kg})\end{array}$ & $\begin{array}{c}\text { Kr capacity } \\
\text { (mmol/kg) }\end{array}$ \\
\hline \hline $\mathrm{Kr} / \mathrm{Xe} /$ Air & 191 & 50 & 468 & 5.3 \\
$\mathrm{Kr} / \mathrm{Xe} / \mathrm{N}_{2} / \mathrm{He}$ & 191 & $69^{*}$ & 429 & 8.3 \\
$\mathrm{Kr} / \mathrm{Xe} / \mathrm{He}$ & 191 & 50 & 864 & 51.3 \\
$\mathrm{Xe} / \mathrm{He}$ & 192 & 50 & 756 & $\mathrm{NA}$ \\
$\mathrm{Kr} / \mathrm{He}$ & 192 & 50 & $\mathrm{NA}$ & 65.8 \\
\hline \hline
\end{tabular}

* The 69 sccm flow rate resulted from using a different mass flow controller.

As expected, the Xe capacities at $191 \mathrm{~K}$ were over an order of magnitude higher than capacities measured at ambient temperature. ${ }^{5}$ As was found with the ambient temperatures, the addition of air did not have a significant impact on Xe capacities at $191 \mathrm{~K}$. However, the addition of air did decrease the $\mathrm{Kr}$ capacity by an order of magnitude. Also, when comparing the $\mathrm{Kr}$ capacity for the $\mathrm{Kr} / \mathrm{He}$ gas composition to the $\mathrm{Kr} / \mathrm{Xe} / \mathrm{He}$ gas composition, a $\mathrm{Kr}$ capacity decrease of about $30 \%$ was measured when $\mathrm{Xe}$ is present. As found in the literature, ${ }^{6} \mathrm{Xe}$ capacity is an order of magnitude higher than $\mathrm{Kr}$ capacity when testing $\mathrm{Xe} / \mathrm{He}$ and $\mathrm{Kr} / \mathrm{He}$ gases and 50 to 80 times higher with gases where $\mathrm{N}_{2}$ and $\mathrm{O}_{2}$ are present. 


\subsubsection{Selectivity of Xe Relative to $\mathrm{Kr}$ at $191 \mathrm{~K}$}

The selectivity of $\mathrm{Xe}$ relative to $\mathrm{Kr}$ was calculated for tests where both $\mathrm{Xe}$ and $\mathrm{Kr}$ capacities were measured using the following equation:

$\mathrm{Sel}_{X e, K r}=\frac{\boldsymbol{X}_{X e} / \boldsymbol{Y}_{X e}}{\boldsymbol{X}_{K r} \boldsymbol{Y}_{K r}}$

Where $X_{X e}$ and $X_{K r}$ are mol fractions of Xe and $\mathrm{Kr}$ in the adsorbed phase, and $\mathrm{Y}_{\underline{X e}}$ and $Y_{K r}$ are mol fractions of $\mathrm{Xe}$ and $\mathrm{Kr}$ in the bulk phase. The $\mathrm{Xe}$ selectivities relative to $\mathrm{Kr}$ for selected test gases are shown in Table 3. Selectivities could only be calculated for tests performed at $191 \mathrm{~K}$, since there was no measurable $\mathrm{Kr}$ capacity at ambient temperature.

Table 3. Xe selectivity relative to $\mathrm{Kr}$ for AgZ-PAN at $191 \mathrm{~K}$.

\begin{tabular}{lc}
\hline \multicolumn{1}{c}{ Feed Gas composition } & Selectivity Xe relative to $\mathrm{Kr}$ \\
\hline \hline $\mathrm{Kr} / \mathrm{Xe} / \mathrm{Air}$ & 13.6 \\
$\mathrm{Kr} / \mathrm{Xe} / \mathrm{N} 2 / \mathrm{He}$ & 7.8 \\
$\mathrm{Kr} / \mathrm{Xe} / \mathrm{He}$ & 2.5 \\
\hline \hline
\end{tabular}

The selectivity of $\mathrm{Xe}$ relative to $\mathrm{Kr}$ with the feed gas composed mostly of air is over five times higher than selectivity of gas absent of $\mathrm{N}_{2}$ and $\mathrm{O}_{2}$. This would suggest the presence of air more impacts the $\mathrm{Kr}$ capacity than the Xe capacity. This would substantiate the possibility of using an ambient temperature polishing column containing AgZ-PAN sorbent upstream of a Kr specific sorbent. However, more work should be completed in this area to determine the impacts of $\mathrm{N}_{2}$ and $\mathrm{O}_{2}$ on the $\mathrm{Kr}$ capacities in the final column and if the same selectivities could be achieved at higher test temperatures.

\subsubsection{Thermal Cycling Effects on AgZ-PAN}

Intermittently, baseline tests using the $\mathrm{Kr} / \mathrm{Xe} / \mathrm{He}$ feed gas were performed on the sorbent at ambient temperature. These tests were intended to ensure that the adsorption/desorption thermal cycles were not impacting the sorbent capacities for Xe. If the Xe calculated capacity remains relatively unchanged after undergoing multiple thermal cycles, the sorbent's thermal stability and cycling assets are validated. The use of this particular feed gas at ambient temperature resulted in obtaining only Xe capacities since $\mathrm{Kr}$ capacities were not measureable. The ambient temperature condition was selected because the tests could be completed in a short time duration minimizing impacts to the desired testing schedule. The ambient tests can be completed in 1 day, whereas the $191 \mathrm{~K}$ tests each take about a week to complete. Xe capacities of $31.6,32.1$ and $31.9 \mathrm{mmol} / \mathrm{kg}$ were measured, indicating that throughout the entire test regime of ambient and $191 \mathrm{~K}$ testing, the sorbent capacity for Xe remained unchanged, revealing the crystalline structure of the AgZ-PAN sorbent was not impacted by the collective adsorption/desorption cycles.

The mass of the AgZ-PAN following removal from the cryostat after testing was measured at $5.368 \mathrm{~g}$. This resulted in an insignificant $5 \%$ weight loss assumed to be residual water vapor removed during desorption cycles. BET surface area analysis of the removed material was measured to be $244 \mathrm{~m}^{2} / \mathrm{g}$, which is in good agreement with the surface area $\left(250 \mathrm{~m}^{2} / \mathrm{g}\right)$ measured prior to testing. The unaffected surface area supports the fact that the material structure is thermally stable under numerous adsorption/desorption thermal cycles. 


\subsubsection{Comparison to HZ-PAN Sorbent}

Capacity results obtained from the FY-11 testing utilizing the HZ-PAN sorbent were compared to capacity results obtained using the AgZ-PAN sorbent. All comparisons are made using identical test gas compositions at $191 \mathrm{~K}$. Table 4 includes the $\mathrm{Xe}$ and $\mathrm{Kr}$ comparison capacity data for HZ-PAN and AgZ-PAN engineered sorbents.

Table 4. Xe and Kr capacity comparisons for HZ-PAN and AgZ-PAN at $191 \mathrm{~K}$.

\begin{tabular}{lcccc}
\hline \hline \multicolumn{1}{c}{ Feed Gas } & $\begin{array}{c}\text { HZ-PAN Xe } \\
(\mathrm{mmol} / \mathrm{kg})\end{array}$ & $\begin{array}{c}\text { AgZ-PAN Xe } \\
(\mathrm{mmol} / \mathrm{kg})\end{array}$ & $\begin{array}{c}\text { HZ-PAN Kr } \\
(\mathrm{mmol} / \mathrm{kg})\end{array}$ & $\begin{array}{c}\text { AgZ-PAN Kr } \\
(\mathrm{mmol} / \mathrm{kg})\end{array}$ \\
\hline \hline $\mathrm{Kr} / \mathrm{Xe} / \mathrm{Air}$ & In progress & 468 & In progress & 5.3 \\
$\mathrm{Kr} / \mathrm{Xe} / \mathrm{N}_{2} / \mathrm{He}$ & 636 & 429 & 7.7 & 8.3 \\
$\mathrm{Kr} / \mathrm{Xe} / \mathrm{He}$ & 1100 & 864 & 11.3 & 51.3 \\
$\mathrm{Kr} / \mathrm{He}$ & $\mathrm{NA}$ & $\mathrm{NA}$ & 104 & 65.8 \\
\hline \hline
\end{tabular}

*This test gas was not available when the HZ-PAN was in the cryostat in FY-11. Testing is currently underway.

The comparison results for Xe capacities at $191 \mathrm{~K}$ indicate the HZ-PAN has higher capacity for Xe than AgZ-PAN for the two gases having $\mathrm{Kr}$ and Xe with or without $\mathrm{N}_{2}$. This is probably due to the higher surface area of the HZ-PAN form at $336 \mathrm{~m}^{2} / \mathrm{g}$, whereas the AgZ-PAN sorbent was measured at $250 \mathrm{~m}^{2} / \mathrm{g}$. The $\mathrm{Kr}$ capacities indicate the HZ-PAN performs very favorably when compared to the AgZ-PAN at $191 \mathrm{~K}$. The primary purpose of this work is to evaluate the performance of the two materials at reduced temperature. As speculated in the FY-10 work, HZ-PAN Kr capacities are very comparable, and in some cases, may actually be better than the more expensive AgZ-PAN at reduced temperature. The HZ-PAN engineered form tested has a higher surface area than the AgZ-PAN tested, which when used at lower temperatures, may allow for higher capacities to be achieved for $\mathrm{Kr}$ and $\mathrm{Xe}$.

\subsection{Conclusions}

An engineered form sorbent AgZ-PAN was prepared and tested in FY-12 at ambient and 191K temperatures with numerous feed gas compositions. Test results using this material were compared to capacity results using the previously engineered form tested in FY-11. At ambient temperature, the AgZPAN has good Xe capacity and immeasurable Kr capacity. There was no measurable capacity for Xe or $\mathrm{Kr}$ for the HZ-PAN ambient temperature testing in FY-11. The higher Xe capacity of the AgZ-PAN at ambient temperature is assumed to occur due to strong interactions of Xe with silver exchanged materials. ${ }^{7,8}$ The AgZ-PAN engineered form may be better served in a Xe polishing column at ambient or slightly higher temperature. The comparison results indicate the AgZ-PAN engineered form actually had lower Xe and $\mathrm{Kr}$ capacities attributed to its lower surface area. However it demonstrated higher Xe and $\mathrm{Kr}$ capacities over the HZ-PAN at ambient temperature. In general, the results of this testing indicate the presence of silver appears to increase capacities at ambient temperature; however, surface area appears to influence capacities at $191 \mathrm{~K}$.

\subsection{Future Work}

Testing utilizing both engineered forms would include sorbents tested in series in the cryostat setup. The AgZ-PAN could be used as a Xe and possibly $\mathrm{N}_{2}$ and $\mathrm{O}_{2}$ polishing column at ambient temperature upstream of the HZ-PAN in the cryostat at reduced temperatures. The selectivities of Xe and $\mathrm{Kr}$ relative to $\mathrm{N}_{2}$ and $\mathrm{O}_{2}$ presence should be further investigated. 
The potential for testing the AgZ-PAN for iodine chemisorption should be investigated. The higher surface area of the engineered form when compared to the commercial Ag-900 pelletized product could provide more silver availability for chemisorption. These tests would need to be completed at temperatures lower than $150^{\circ} \mathrm{C}$ due to the potential decomposition of the binder at elevated temperature. Additional preparations of the AgZ-PAN are planned to supply ORNL/INL iodine team members with material to test in deep bed systems. 


\section{NON-DESTRUCTIVE GAMMA SCAN ANALYSIS OF KR-85 LEGACY SAMPLES}

INL Contributors: Mitchell Greenhalgh, Troy Garn, Chris Oertel, John Giles and Brian Storms

\subsection{Introduction}

The purpose of this section is to report the progress towards meeting the objectives as outlined in the Strategy for Analysis of Legacy Kr-85 Samples documented in FY-11. ${ }^{9}$ This document included a threestage strategy for analyzing the contents of a drum containing both hot-isostatically pressed (HiPed) and "loose" zeolyte samples salvaged prior to CPP-602 reprocessing facility decontamination and decommissioning efforts. Stage one of the strategy defined the preliminary steps of determining radiation and contamination levels prior to opening the drum, removing the contents, and repackaging samples to allow for future analyses. This report completes the radiation determinations portion of stage one on the outer container only. Due to safety stand downs occurring at the Materials and Fuels Complex (MFC) throughout FY-12, future efforts to continue with the strategy plan have currently been put on hold.

\subsection{Gamma Scan Analysis of Container}

This section presents results of qualitative gamma scans performed in the Hot Fuels Examination Facility (HFEF) on a 20 gallon over-pack drum suspected of containing $\mathrm{Kr}-85$ in various containers. The drum was labeled as CWIID-0000733577.

The purpose of these measurements was to verify the presence of $\mathrm{Kr}-85$ in the drum, and to assess whether any other significant gamma ray emitters were present in the radioactive matrices in addition to $\mathrm{Kr}-85$. Krypton- 85 emits a very strong gamma ray at $514 \mathrm{KeV}$ and has a half life of 10.7 years. In order to assess the possible presence of other gamma emitters, an ORTEC ${ }^{\circledR}$ Detective high purity Germanium detection system was used. This unit is portable and electomechanically cooled. Prior to scanning the drum, the system was checked for proper energy calibration using a NIST-traceable Cs-137 point source.

The detector was placed approximately 3 feet from the drum face as shown in Figure 3 and four scans lasting 15 minutes each were taken. The spectral data from each scan was stored onboard the system and post-processed using PeakEasy version 4.02. The drum was rotated 90 degrees between scans in order to ensure that the entire matrix was scanned.

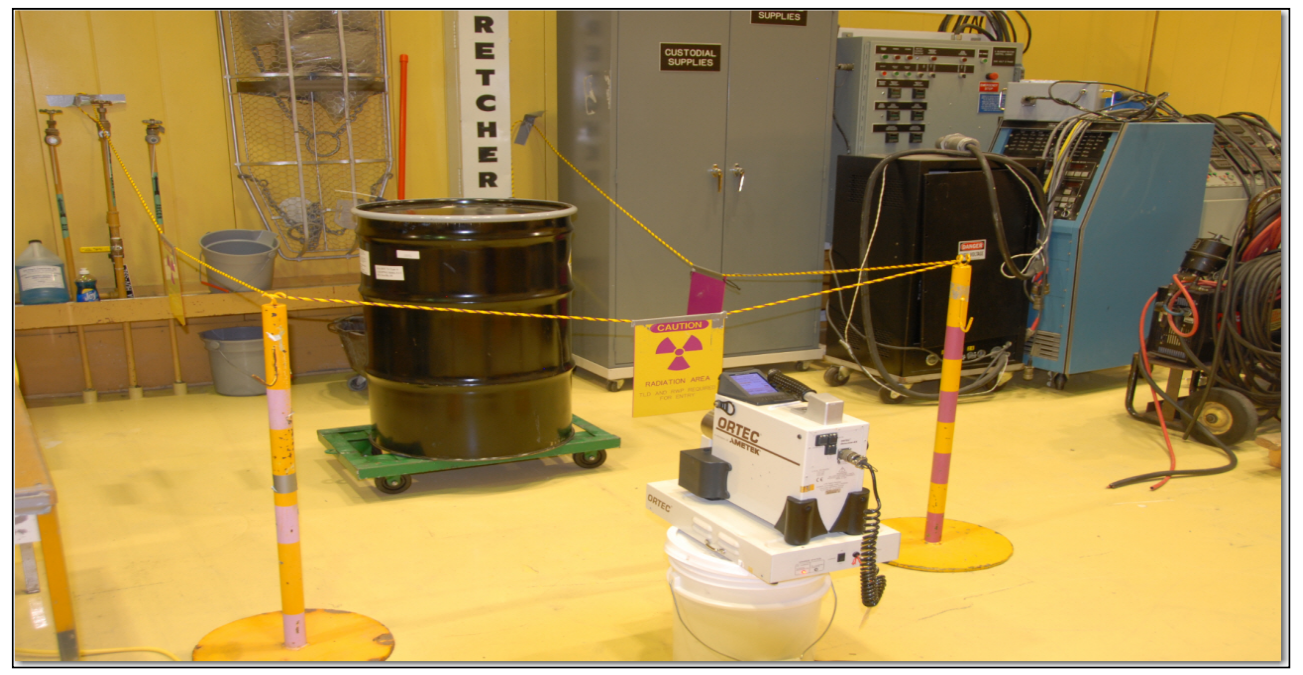

Figure 3. Drum containing Kr-85 samples with gamma scan equipment in HFEF at MFC. 


\subsection{Results}

Table 5 shows the gross gamma count rate and dose rate values from each of the four scans.

Table 5. Results of gamma scans.

\begin{tabular}{ccc}
\hline \hline Drum Side & $\begin{array}{c}\text { Count Rate } \\
(\mathrm{cps})\end{array}$ & $\begin{array}{c}\text { Dose Rate } \\
(\mathrm{mR} / \mathrm{hr})\end{array}$ \\
\hline \hline 1 & 10320 & 0.58 \\
2 & 6258 & 0.35 \\
3 & 4893 & 0.27 \\
4 & 4142 & 0.22 \\
\hline \hline
\end{tabular}

Table 5 shows that side 1 exhibited the highest count and dose rate values, indicating that the radioactive material may be packed slightly to that side of the drum or that there is less shielding on that side of the drum. Figures 4-7 show the gamma scan results from each side. The four spectra are very similar, indicating that the identified radionuclides in the drum are consistent throughout the drum. All four spectra showed the presence of Kr-85, Cs-137, Co-60, K-40, and Tl-208. The latter two isotopes are naturally occurring isotopes. In order to assess the presence or absence of Cs-137 and Co-60, the count rates from the four acquired spectra were evaluated. Table 6 shows these results. The very low and internally consistent count rate values indicate that Cs-137 and Co-60 are most likely present as background rather than as part of the radionuclide content of this drum. As expected, the prominent gamma emitting isotope present in this drum is $\mathrm{Kr}-85$.

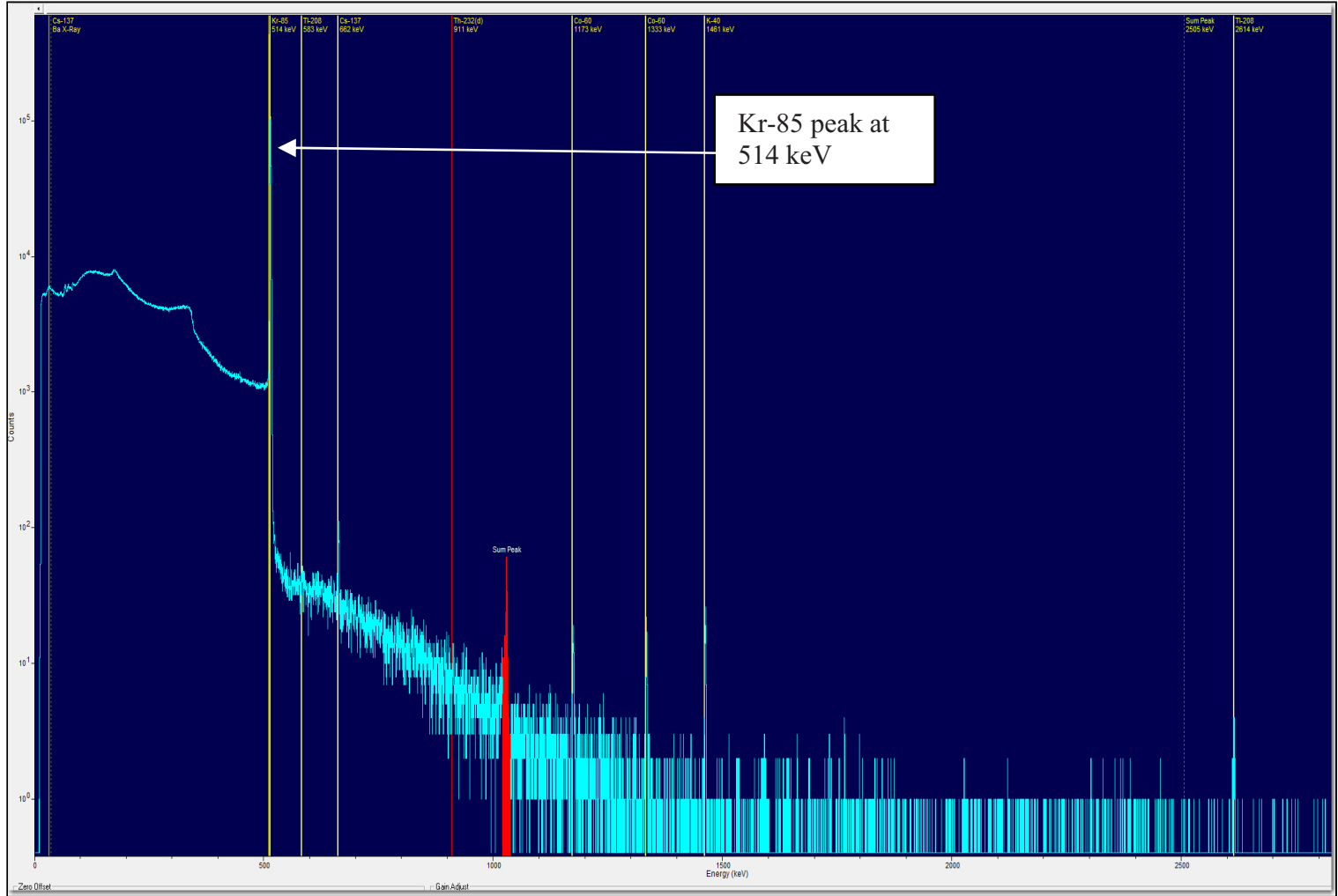

Figure 4. Drum side 1: Identified peaks include Kr-85, Cs-137, Co-60, Sum peaks, Tl-208. 


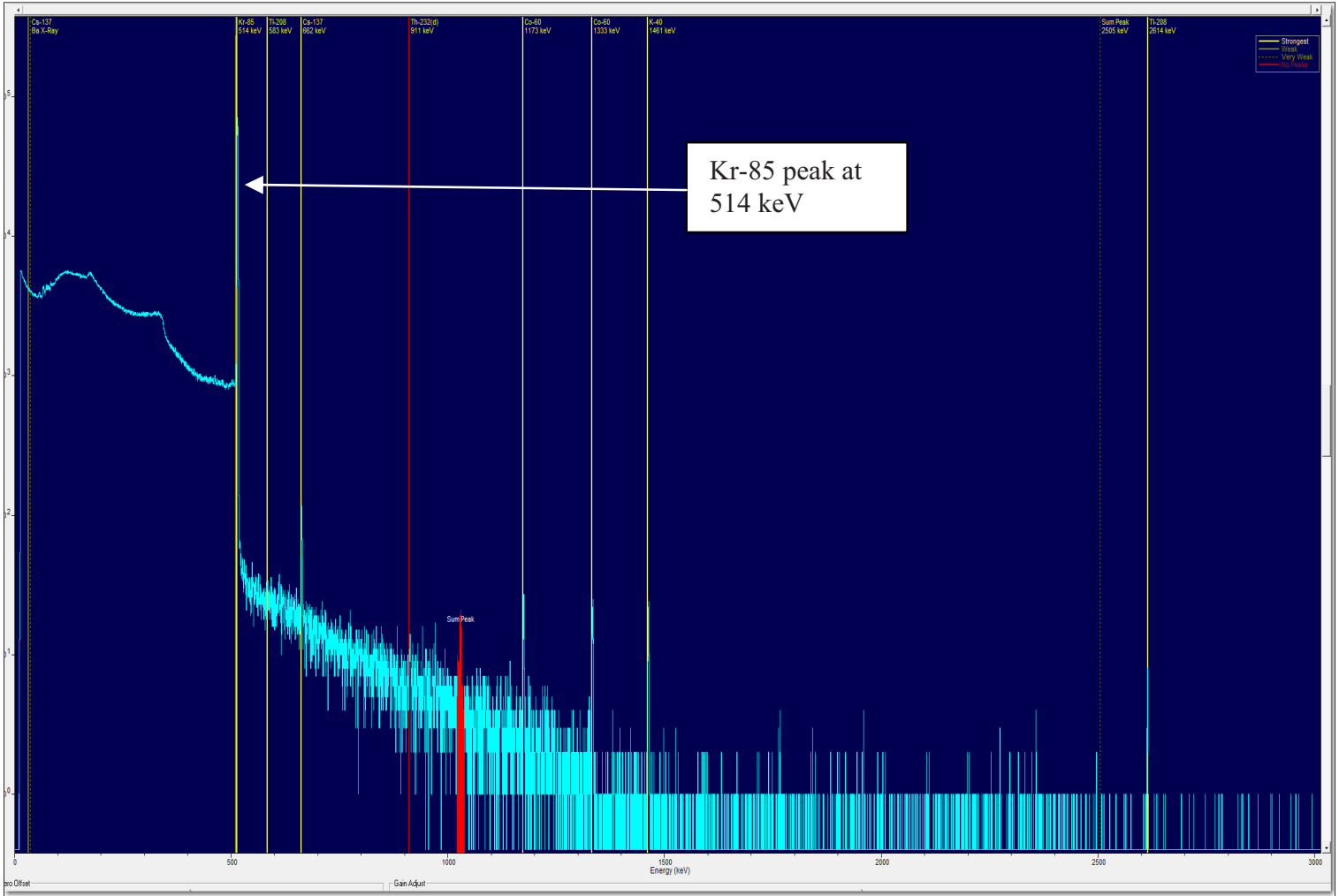

Figure 5. Drum side 2: Identified peaks include Kr-85, Cs-137, Co-60, Sum peaks, Tl-208.

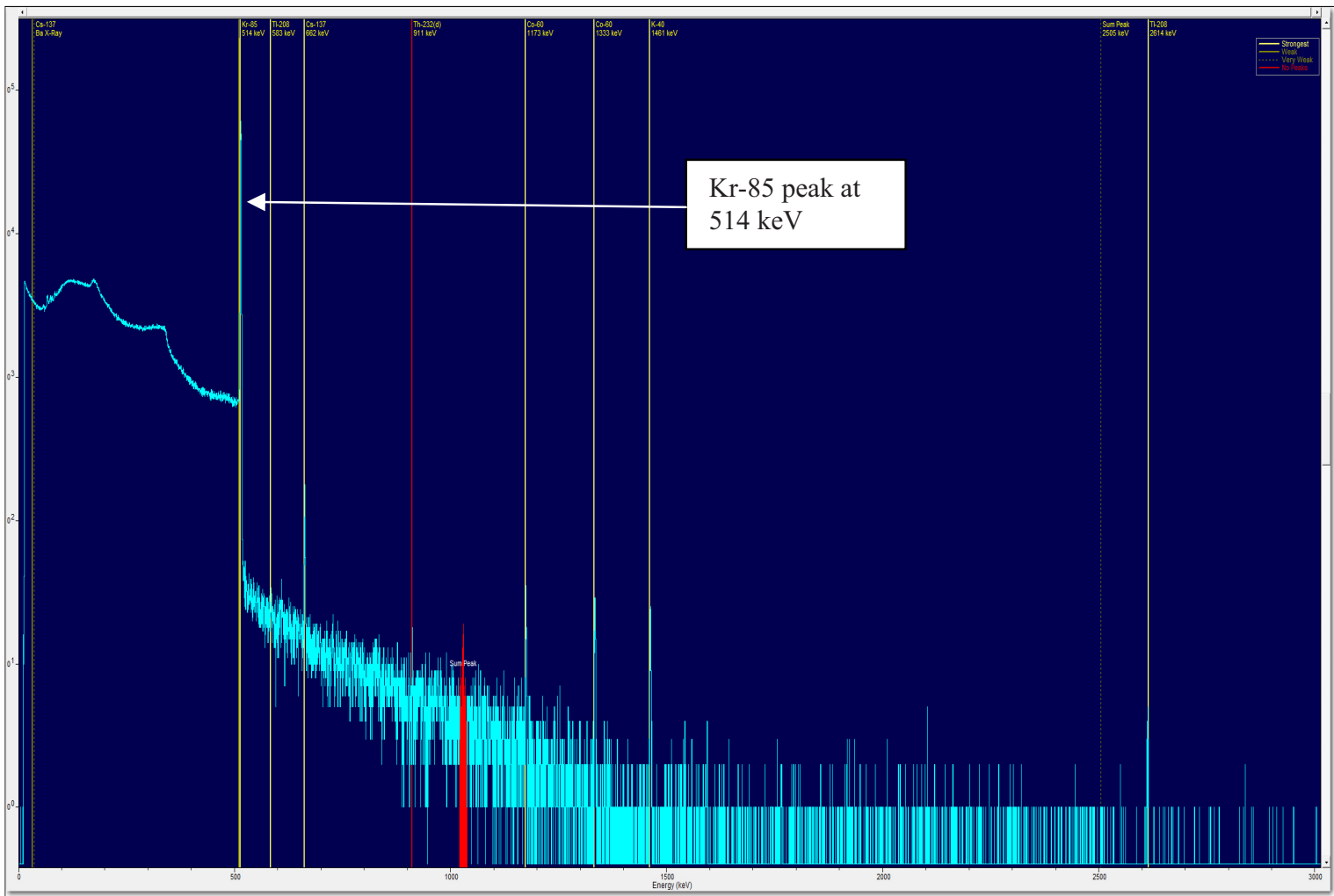

Figure 6. Drum side 3: Identified peaks include Kr-85, Cs-137, Co-60, Sum peaks, Tl-208. 


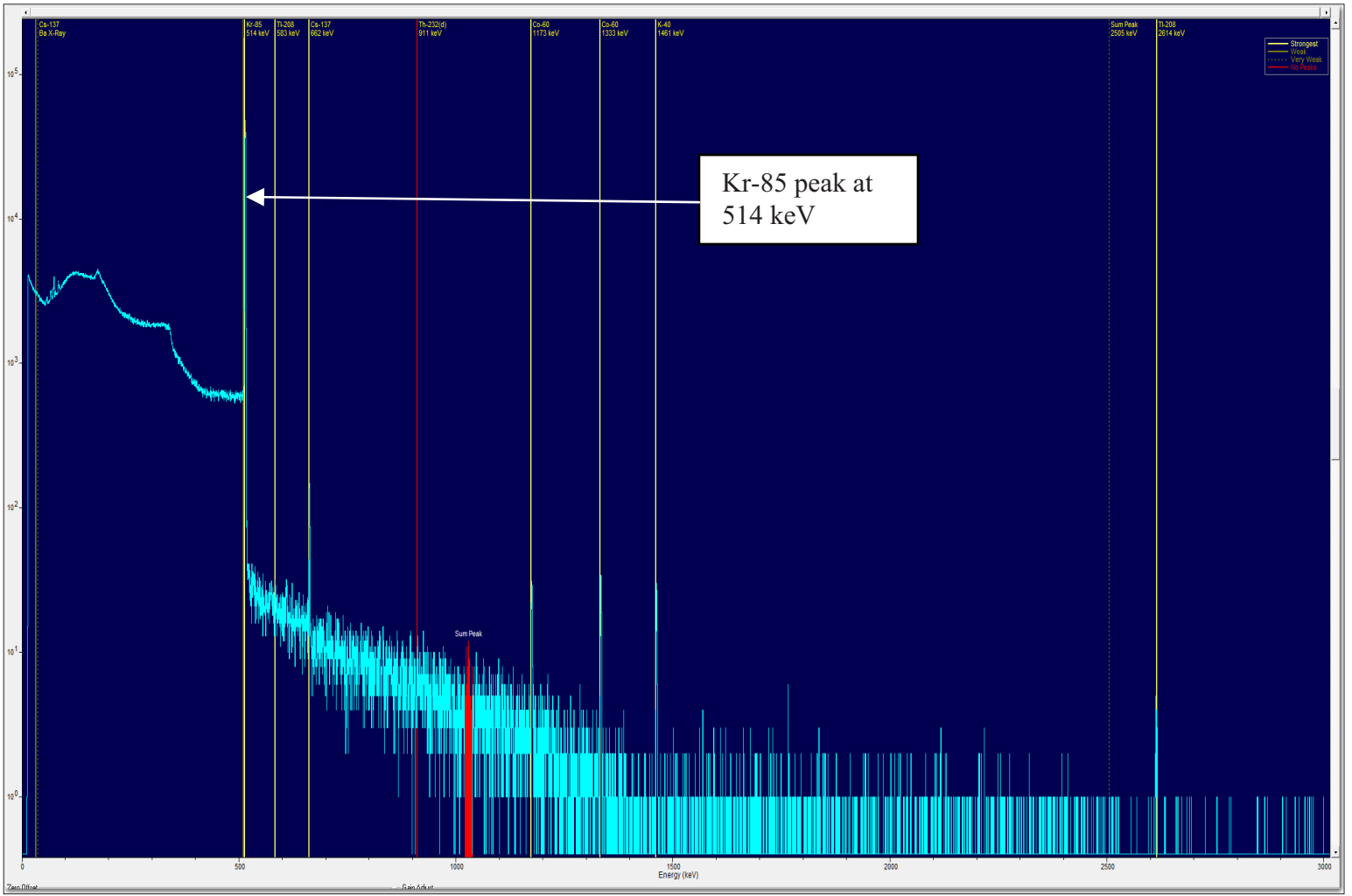

Figure 7. Drum side 4: Identified peaks include Kr-85, Cs-137, Co-60, Sum peaks, Tl-208

Table 6. Cs-137 and Co-60 count rate values for four drum sides.

\begin{tabular}{ccc}
\hline \hline Drum Side & $\begin{array}{c}\text { Cs } 137 \\
(\mathrm{cps})\end{array}$ & $\begin{array}{c}\text { Co-60 } \\
\text { (cps) }\end{array}$ \\
\hline \hline 1 & 1.88 & 0.21 \\
2 & 1.25 & 0.25 \\
3 & 1.31 & 0.25 \\
4 & 1.34 & 0.29 \\
\hline \hline
\end{tabular}

\subsection{Conclusions}

Gamma scan results indicate the prominent gamma emitting isotope present in the drum is $\mathrm{Kr}-85$. At the time of this writing, it is uncertain if the tasks documented in the strategy plan developed in FY-11 will be completed. The accomplishment of tasks at MFC relating to research involving radiation and potential contamination has become more difficult due to the backlog of work related to safety stand downs. As such FY-13 work should include discussion into alternative or reduced work scope aside from that documented in the strategy plan. 


\section{PNNL COLLABORATIONS}

INL contributors: Troy Garn, Mitchell Greenhalgh, Veronica Rutledge, Cathy Rae, Jack Law PNNL contributors: Praveen Thallapally, Brian Riley, Denis Strachan, John Vienna

\subsection{Testing of Ni-DOBDC MOF}

\subsubsection{Introduction}

A meeting was held at the Idaho National Laboratory (INL) on February 9, 2012 to discuss and agree on future testing of metal organic frameworks (MOFs) to be performed at the INL. In attendance at this meeting were Praveen Thallapally from Pacific Northwest National Laboratory (PNNL), and Mitchell Greenhalgh, Troy Garn, Veronica Rutledge, and Jack Law from INL. Test conditions for adsorption tests to be performed using the cryostat experimental setup at the INL were discussed. A final test plan was written to describe test conditions for a Xe specific MOF (Ni-DOBDC) supplied to the INL by PNNL.

\subsubsection{Experimental}

A cylinder of gas with a composition of $150 \mathrm{ppm} \mathrm{Kr}, 1000 \mathrm{ppm} \mathrm{Xe}, 79 \%$ nitrogen and $21 \%$ oxygen was acquired and used for all testing. The arrival of the gas was nearly 3 weeks later than expected, resulting in an unanticipated delay in the start of testing. While waiting for the gas to arrive, surface area measurements for the MOF material were performed using a model ASAP 2020 Micromeritics Surface Area Analyzer. As recommended from PNNL, a 0.1 gram MOF sample was degassed at $200^{\circ} \mathrm{C}$ under vacuum for 10 hours prior to performing BET analysis. The surface area from this initial BET analysis was only $182 \mathrm{~m}^{2} / \mathrm{g}$ in the $\mathrm{P} / \mathrm{P}_{\mathrm{o}}$ range of $0.06-0.13$, which was unexpectedly low. There was also a slight color change resulting from BET analysis from yellow to a more brownish hue. This was normal as indicated by Dr. Thallapally. The reported surface area for this particular MOF is $\sim 800 \mathrm{~m}^{2} / \mathrm{g}$. After discussing the low surface area with Dr. Thallapally, it was suggested we submit a portion of the MOF sample as received for powdered x-ray diffraction (PXRD) analysis. Results for the PXRD analysis are included in Figure 8. After communications with PNNL staff it was determined the results of the PXRD analyses were very comparable to those observed at PNNL. The results of the PXRD analyses did not provide a good explanation for the low surface area measurement, however it did indicate the crystal characterization of the material agreed favorably with PNNL results.

\subsubsection{Actual Testing in Cryostat}

A mass of 4.6566 grams of MOF material was loaded into the cryostat sample column. The material was activated for 16 hours at $200^{\circ} \mathrm{C}$ while flowing helium at $50 \mathrm{sccm}$ across the column bed. Three tests were performed at $297 \mathrm{~K}$ while varying test gas flow rates at 10,20 and $50 \mathrm{sccm}$ (superficial velocity range of 0.2 to $1.2 \mathrm{~cm} / \mathrm{s}$ ). A $200^{\circ} \mathrm{C}, 10$ hour desorption was performed following each test. After obtaining breakthrough data from the GC results, Xe and $\mathrm{Kr}$ capacity calculations were performed for each flow rate. The capacity results for these first tests indicated there was no measurable capacity for Xe or $\mathrm{Kr}$ at the tested conditions. Capacity calculation accuracy is dependent on the experimental process design, including a relatively large dilution volume relating to interior cryostat dimensions as well as analytical detection limits associated with the developed GC methodology. These two design limitations contribute to difficulties in measuring the lower capacities. A second set of identical test conditions were tested in a column situated outside the cryostat in an attempt to alleviate the dilution volume of the cryostat interior. 

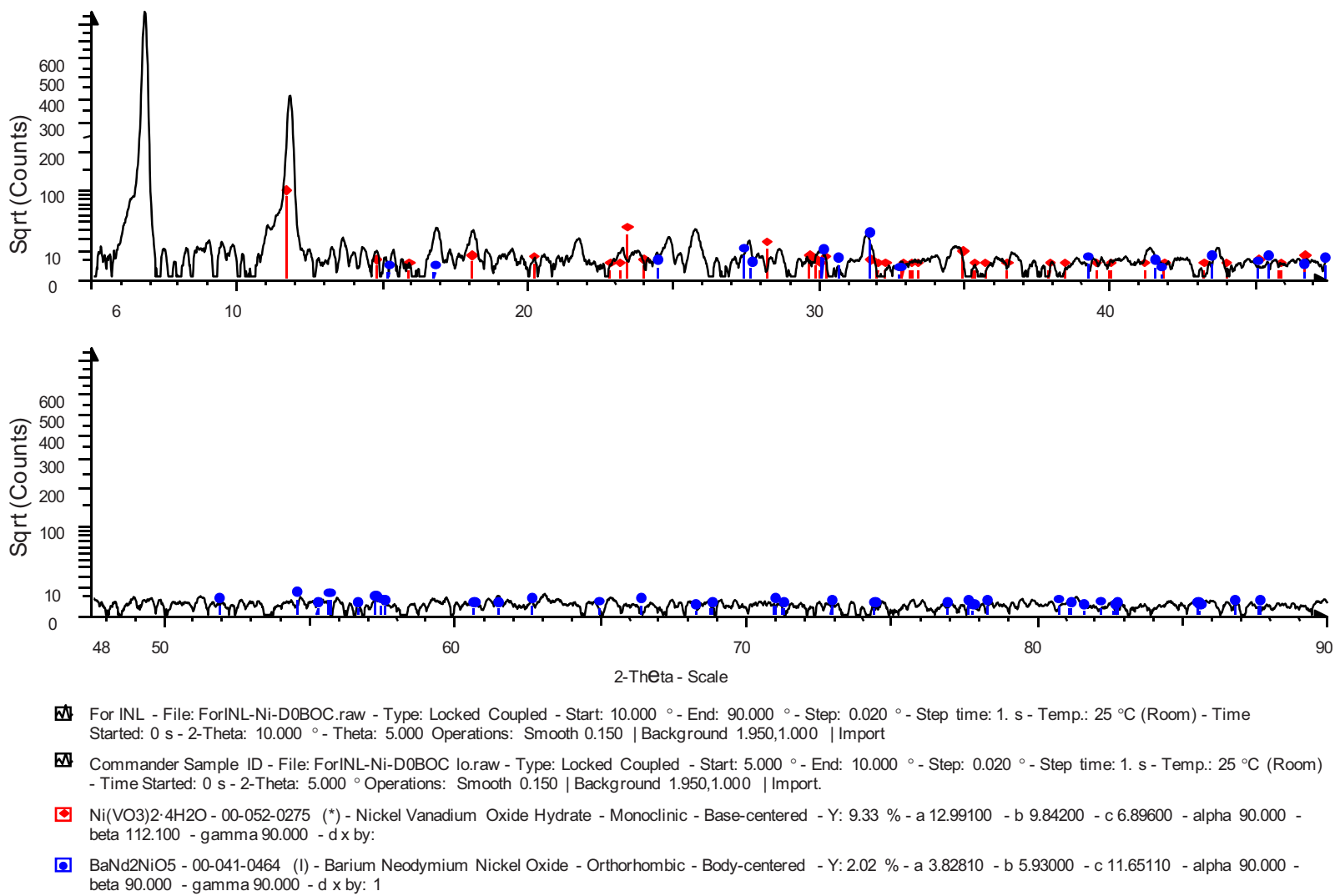

Figure 8. PXRD results for MOF as received

Following the testing in the cryostat setup, the equipment was disassembled and the MOF sorbent was removed from the column. The MOF was weighed for observation of weight loss/gain. The weight of the MOF was initially measured at 3.140 grams but continued to increase to 3.579 grams over 16 hours. This resulted in an estimated overall weight loss of 1.083 grams, which was assumed to be water vapor being expelled from the material during the $200^{\circ} \mathrm{C}$ activation steps.

A second PXRD analysis was performed on a subsample of the MOF material removed from the cryostat with spectra results included in Figure 9. A comparison of the PXRD spectra of the MOF material before and after use indicate little if any crystalline change resulted from testing.

A second BET measurement was made on a portion of the material tested in the cryostat using identical degas conditions as first BET measurement. The surface area result was $592 \mathrm{~m}^{2} / \mathrm{g}$ at a P/P orange of 0.06 to 0.13 . Although this is still below the expected surface area, it is higher than the initial BET result on the as received material. This also indicates the multiple activation iterations contributed to the increased surface area. 


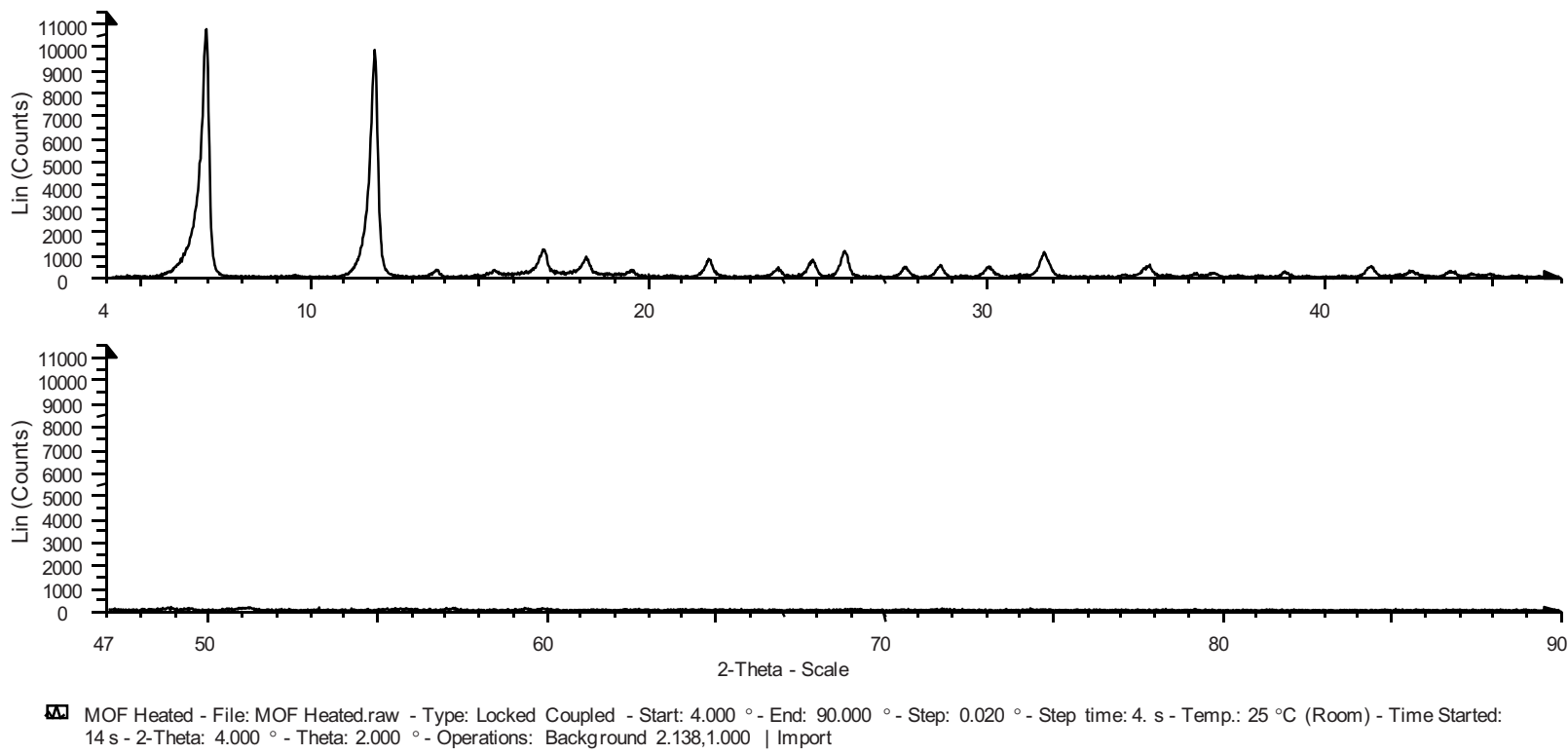

Figure 9. PXRD results for MOF following activation at $200^{\circ} \mathrm{C}$.

\subsubsection{Testing in ambient temperature column outside of cryostat}

A mass of 3.249 grams of the MOF was placed in a $3 / 8$ in. inside diameter $\times 2.5 \mathrm{in}$. long stainless steel column and heated to $200^{\circ} \mathrm{C}$ using heat tape with a temperature controller while flowing helium at $50 \mathrm{sccm}$ through the column for 16 hours. Test gas flow rates of 10, 20, and $50 \mathrm{sccm}$ (superficial velocity range of 0.2 to $1.2 \mathrm{~cm} / \mathrm{s}$ ) were repeated for this test series. A volume dilution test was performed for each flow rate by flowing test gas bypassing column to calculate the moles of gas accumulating in the experimental setup tubing which was subtracted from the total moles of gas adsorbed in the capacity calculations. Table 7 includes the Xe capacity results for each flow rate tested. Krypton capacity was also calculated for the $10 \mathrm{sccm}$ flow rate test and added to the table for reference.

Table 7. Xe and $\mathrm{Kr}$ capacity at varying test gas flow rate at ambient temperature.

\begin{tabular}{cccc}
\hline \hline $\begin{array}{c}\text { Flow Rate } \\
(\mathrm{sccm})\end{array}$ & $\begin{array}{c}\text { Temperature } \\
\left({ }^{\circ} \mathrm{C}\right)\end{array}$ & $\begin{array}{c}\text { Xe capacity } \\
(\mathrm{mmol} / \mathrm{kg})\end{array}$ & $\begin{array}{c}\text { Kr capacity } \\
(\mathrm{mmol} / \mathrm{kg})\end{array}$ \\
\hline \hline 50 & 23.0 & 9.82 & $\mathrm{n} / \mathrm{a}$ \\
20 & 22.7 & 7.57 & $\mathrm{n} / \mathrm{a}$ \\
10 & 21.0 & 7.35 & 0.15 \\
\hline \hline
\end{tabular}

The Xe capacities compare quite favorably with those data reported in the limited literature (Dr. Thallapally reported $9.31 \mathrm{mmol} / \mathrm{kg}$ Xe capacity using a Xe gas concentration of $1000 \mathrm{ppm}){ }^{10}$ The reported $\mathrm{Kr}$ capacity of $0.15 \mathrm{mmol} / \mathrm{kg}$ at $10 \mathrm{sccm}$ flowrate was calculated using a gas with a $\mathrm{Kr}$ concentration of $150 \mathrm{ppm}$. Dr. Thallapally reported a $\mathrm{Kr}$ capacity of $0.066 \mathrm{mmol} / \mathrm{kg}$ using a $\mathrm{Kr}$ gas concentration of $40 \mathrm{ppm}$. It is speculated that the higher capacity is due to the higher $\mathrm{Kr}$ gas concentration, however a $0.15 \mathrm{mmol} / \mathrm{kg}$ capacity is approaching the detection limits of the GC-TCD analytical system used at INL. 


\subsubsection{Conclusions}

Capacities could not be determined from the initial tests using the cryostat experimental setup. The volume dilution from the equipment interior inhibited the calculation of the lower capacities. The experimental setup is designed for lower temperature testing. Results of tests performed with the ambient temperature column however, indicate excellent agreement with previously reported data.

There was a surprisingly high mass loss of material observed from assumed initial testing activation steps. Accurate mass measurements were difficult to achieve because of losses/gains attributed to water vapor release or capture. This is apparently a normal characteristic of the MOF material.

\subsubsection{Future Work}

As a result of the inability to measure $\mathrm{Kr}$ capacity of the Ni-DOBDC because of the dilution volume associated with the cryostat setup and small sample mass, PNNL will prepare and send an additional 20 to $30 \mathrm{~g}$ of Ni-DOBDC material to retest in the cryostat. Tests will be performed at ambient temperature with a higher sample mass in an attempt to accurately measure $\mathrm{Kr}$ capacities. If desired, there may also be opportunity to evaluate the Ni-DOBDC material at reduced temperatures for $\mathrm{Kr}$ and $\mathrm{Xe}$ capacity.

PNNL staff is also developing a MOF that is designed to have a higher selectivity for $\mathrm{Kr}$ than the Ni-DOBDC material. A sample of this material may be received and tested in the cryostat in the latter part of FY-13.

\subsection{Engineered Forms of Chalcogel Powders}

\subsubsection{Introduction}

The INL received two chalcogel powder samples labeled as PNNL-1 and PNNL-3. PNNL-1 was designated as $\left(\mathrm{Co}_{0.7} \mathrm{Cr}_{0.3} \mathrm{MoS}_{4}\right)$ and PNNL-3 as $\left(\mathrm{Co}_{0.7} \mathrm{Bi}_{0.3} \mathrm{MoS}_{4}\right)$. The purpose of this work was to perform a preliminary scoping effort as to the possibility of preparing an engineered form material from the chalcogel powders using the INL sorbent development binding process.

\subsubsection{Experimental}

BET measurements of both powder samples were made prior to preparing an engineered form. INL BET results were $185 \mathrm{~m}^{2} / \mathrm{g}$ and $454 \mathrm{~m}^{2} / \mathrm{g}$ for PNNL-1 and PNNL-3, respectively. BET measurements obtained from PNNL for the two powders were $441 \mathrm{~m}^{2} / \mathrm{g}$ and $511 \mathrm{~m}^{2} / \mathrm{g}$ for PNNL-1 and PNNL-3 respectively. Since the BET measurements for PNNL-3 were in good agreement, it was selected as the candidate to investigate if an engineered form material could be prepared.

An initial effort was made to bind the PNNL-3 powder into an engineered form. Contacting the powder with our solvent at a typical powder to solvent ratio before applying the macroporous binder resulted in a very viscous mixture. Solvent was continuously added until the mixture was deemed appropriate for adding the binder. After adding the binder, the beads were formed. A final engineered form was achieved with a composition estimated at $55 \mathrm{wt} \%$ chalcogel and $45 \mathrm{wt} \%$ binder. A photograph of the final formed beads is shown in Figure 10. The average particle diameter is estimated to be 1.5 to $2.0 \mathrm{~mm}$. A BET measurement of the engineered beads resulted in a surface area of only $50 \mathrm{~m}^{2} / \mathrm{g}$, which was much lower than expected. Since the chalcogel in the engineered form was about $55 \mathrm{wt} \%$ one would expect the surface area to be about $55 \%$ of $454 \mathrm{~m}^{2} / \mathrm{g}$ or $250 \mathrm{~m}^{2} / \mathrm{g}$. 


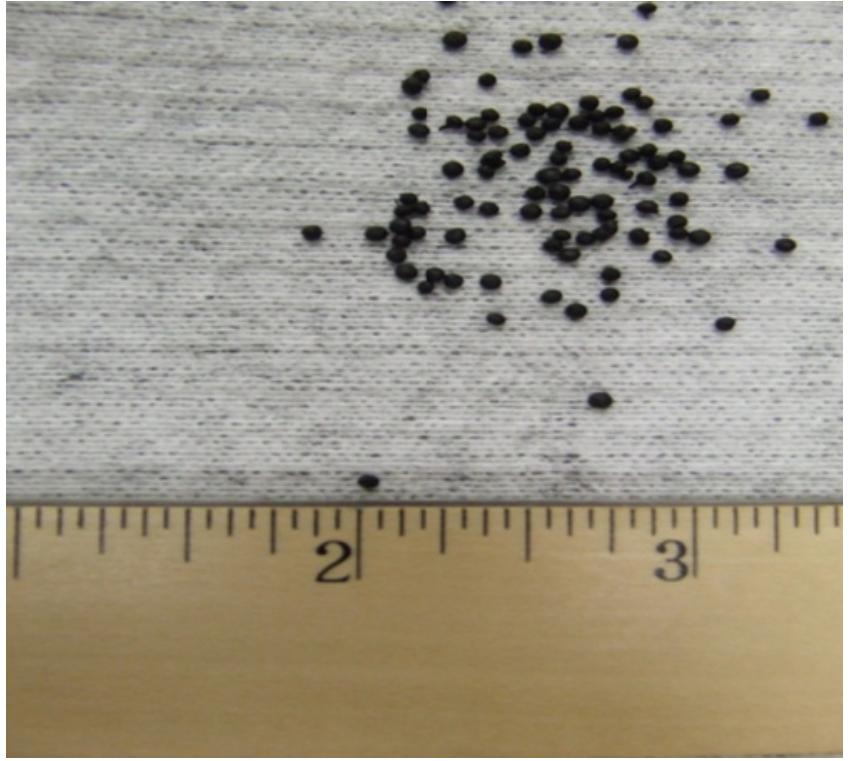

Figure 10. Photo of engineered form PNNL-3 chalcogel.

Communications with PNNL staff suggested that exposing the chalcogel powders to a solvent could potentially collapse them to xerogels, resulting in significant decreases in surface area. This anomaly can be mitigated by drying the materials after solvent contact with a supercritical fluid. The inclusion of super critical fluids with our binding process has not been investigated. This is the most likely explanation for the lower surface area of the engineered form. The PNNL-1 and PNNL-3 powders along with the engineered form beads were returned to PNNL for observation and characterization.

\subsubsection{Future Work}

New samples have been supplied by PNNL. The samples are composed of a powder and a pressed material. Once the materials have been accepted for use and included in the INL safety documentation, attempts will be made to make engineered forms from these new tin sulfide containing samples. Surface area analyses will also be completed. 


\section{REFERENCES}

1. MITCHELL GREENHALGH, TROY GARN, KRISTI CHRISTENSEN, VERONICA RUTLEDGE, JACK LAW, "Summary of FY-11 Krypton Capture Activities at the Idaho National Laboratory," FCRD-SWF-2011-000312, August 2011.

2. GARN, T.G., LAW, J.D, GREENHALGH, M.R, TRANTER, T.J., "A Composite Media For Fluid Stream Processing, A Method Of Forming The Composite Media, And A Related Method Of Processing A Fluid Stream" 2939-10703 BA-590 Patent Application.

3. YONGZHI WANG, QINGBIAO YANG, GUIYE SHAN, CE WANG, JIANSHI DU, SHUGANG WANG, YAOXIAN LI, XUESI CHEN, XIABIN JING, YEN WEI, "Preparation of silver nanoparticles dispersed in polyacrylonitrile nanofiber film spun by electrospinning," Materials Letters 59 (2005) 3046-3049.

4. HUARONG LIU, XUEWU GE, YONGHONG NI, QIANG YE, ZHICHENG ZHANG, "Synthesis and characterization of polyacrylonitrile-silver nanocomposites by $\gamma$ irradiation," Radiation Physics and Chemistry 61 (2001) 89-91.

5. IANOVSKI, D., MUNAKATA, K., KANJO, S., YOKOYAMA, Y., KOGA, A., YAMATUSUKI, S., TANAKA, K. FUKUMATSU, T., NISHIKAWA, M., IGARASHI, Y., "Adsorption of Noble Gases on H-Mordenite," Journal of Nuclear Science and Technology, 39(11), 1213-1218.

6. MUNAKATA, K., KANJO, S., YAMATSUKI, S., KOGA, A., IANOVSKI, D., “Adsorption of Noble Gases on Silver-Mordenite," Journal of Nuclear Science and Technology, 40(9), 695-697.

7. GROSSE, R., BURMEISTER, R., BODDENBERG, B., GEDEON, A., FRAISSARD, J., Journal Physical Chemistry. 1991, 95, 2443.

8. GROSSE, R., GEDEON, A.,WATERMANN, J., FRAISSARD, J., BODDENBERG, B., Zeolytes 1992, $12,909$.

9. TROY G. GARN, MITCHELL R. GREENHALGH, JACK D. LAW, "Strategy for Analyses of Legacy Kr-85 Samples,” INL/MIS-10-20449, FCRD-SEPA-2011-000027, Dec 2010.

10. JIAN LIU, PRAVEEN THALLAPALLY, DENIS STRACHAN, "Metal-Organic Frameworks for Removal of Xe and Kr from Nuclear Fuel Reprocessing Plant," Langmuir manuscript May 2012. 